\title{
An empirical study of information technology clusters and regional economic growth in Russia
}

\author{
Tatiana Kudryavtseva ${ }^{1}$, Dmitry $_{\text {Rodionov }}{ }^{1}$, and Angi Skhvediani ${ }^{1 *}$ \\ ${ }^{1}$ Peter the Great St. Petersburg Polytechnic University, Engineering and Economical Higher School, \\ 195251, Politekhnicheskaya st., 29 Russian Federation
}

\begin{abstract}
The paper is devoted to the identification of the "Information Technologies" cluster in the regions of the Russian Federation and verification of the assumption that there is an interaction between the degree of cluster representation in the region and the GRP size. The authors considered the main theoretical and methodological provisions concerning the identification of clusters with the Top-down approach. Based on the develops of M. Porter and G. Lindqvist, the "Information Technologies" cluster characteristics such as local content, size and focus were calculated for 80 regions of the Russian Federation. The conclusions about the specifics of the cluster development in the country were made. Using the methods of regression analysis, the authors tested a number of hypotheses and revealed the presence of a positive interaction between the GRP volume and the "Information Technologies" cluster presence in the regions of the Russian Federation, as well as the local content, size and focus of this cluster in the regions of the Russian Federation.
\end{abstract}

\section{Introduction}

Regional economic growth is a relevant studies trend [1]. Issues related to the relationship between the economic growth and development of information technologies in separate countries and regions are also the subject of many scientific studies $[2,3,4,5,6]$. In particular, in terms of the development and institutionalization of the concepts "digital economy" [7, 8] and "sixth technological mode" [9] which is based on the convergence of nanotechnologies, biotechnologies, information technologies and cognitive science, the authors deem that it is advisable to perform an empirical study on the analysis of information technologies cluster development in the regions of the Russian Federation and the identification of the relationship between its characteristics and regional economic growth.

The information technologies are one of the drivers of economical growth in the modern world. Mainly, the studies related to the assessment of ICT effect on the economical growth at the national level are divided into two large categories. The first category includes the studies which reflect ICT interest bearing deposit to GDP growth. For example, the studies of M. Timmer, G. Ypma \& B. Van Ark [10], D. Jorgenson \& K. Vu [12] et al. The second group includes the studies using the cross-country methods of regression analysis to assess the ICT effect on the economical growth. This category include studies of Z. Latif, S. Latif,

*Corresponding author: aeskhvediani@mail.ru 
L. Ximei, Z. H. Pathan, S. Salam, \& Z. Jianqiu [13], T. Niebel [14], et al. In this case, the studies of the second group are usually devoted to two problems:

- assessment of the impact of investments in ICT on the economic growth of the regions;

- assessment of the impact of technologies penetration and distribution, their level of use on economic growth.

In this case, the problem of the influence of the cluster structure considered from the perspective of the macro level and, in particular, the ICT cluster on the economic growth of the regions remains open and little presented in the literature.

Thus, the study purpose is to find the relationship between the regional economic growth and the development of the "Information Technologies" cluster in the Russian Federation. To achieve this goal, the authors revealed the main theoretical and methodological provisions related to the identification of clusters using the top-down approach, estimated the local content, size and focus of the cluster group "Information Technologies" in 80 regions of the Russian Federation in the period from 2008 to 2016, marked the significant clusters and built four groups of regression models reflecting the positive relationship between the development of the "Information Technology" cluster and the real GRP growth in the region.

\section{Cluster and its identification}

One of the key aspects of the cluster theory is the problem of clusters identification within separate territories - regions. As foreign experience shows, the existing methodological approaches with a low variety of tools differ considerably in practice. There are many pairs of categories for characterizing the process and techniques for clusters identification, however, most of them are based on two main approaches [15]. In the first approach that can be called "down", the clusters are identified in a specific area based on the presence of enterprises and industries-leaders known in advance. The second approach uses a technique conventionally called "top" where spatially localized industries oriented to the specific types of economic activity are detected. Further, to detect and perform initial analysis of specific regional clusters, a nationwide reference sample is used.

The meaning of "reference" clusters is to determine the types of economic activity which are most often located near each other, and, therefore, have the effect of complementarity. Since "the degree to which the industries actually colocalized in the space indicates the importance of local inter-industry contacts" [16], if spatial affinity is between two or more industries, it will serve to synergy the cluster specialization industries.

The approaches to identification of clusters "top", taking into account two invariable characteristics of clusters - functional connectivity and geographical proximity - are conventionally divided into 2 types: 1) functional, focused on detection of certain types of the clusters;2) spatial, focused on detection of the geographic clusters.

It is now generally recognized that the best results of identification of the clusters "top" are achieved through a combination of functional and spatial approaches. Such synthetic approaches include the approach of M. Porter. The M. Porter's method became classic and one of the most widespread in other countries. Many European and a few domestic attempts to identify and map the clusters do not just use the Harvard approach as the technique, but are based on its results.

As a result of numerous studies, M. Porter was able to fully determine the structure of "reference" clusters based on the variety of activities represented in the American Classifier SIC (Standard Industrial Classification) [17].

Subsequently, the "reference" cores of the cluster groups were widely used by the US Department of Commerce, which supports the project of US clusters mapping [18]. The composition of the "reference" cluster core was adapted for the European Union taking into 
account the application of the European NACE classifier in the project of the European cluster observatory for identification and mapping of economic agglomerations of the EU countries [19].

Full adaptation of foreign Standard Industrial Classification to the Russian analogue OKVED has not been carried out to date.

The solution of this problem by adapting the structure of the "reference" cluster cores for the Russian economy in accordance with the Standard Industrial Classification OKVED will allow determining the composition of the most probable cores of cluster groups of RF entities and can be widely used as an adequate basis for approbation of foreign methods of cluster analysis.

\section{Top - down approach for cluster identification}

In the framework of the "top" approach, the filling of cluster groups within the territory of the federation entities in accordance with the identified "standards" allows to form conditional clusters, but the clusters identification suggests confirmation of the hypothesis of their existence within the specified territory that can be achieved with the use of statistical tools in accordance with the methodology proposed by the European cluster observatory [19].

The presence and development of positive economic externalities affecting the activities of enterprises included in the cluster is determined by the presence of a certain "critical mass" of the cluster group core. As a consequence, the formed "reference" cores of the cluster groups shall be investigated for the presence of specified "critical mass" that determines the relative strength and competitiveness of the local cluster.

This method is based on the assumption that the volume and qualitative level of knowledge circulating between enterprises and organizations included in the cluster under investigation depends on the cluster size, its specialization level, and the extent to which the studied region is aimed at products production in related areas included in the cluster. These 3 factors are determined by the European cluster observatory as the "Localization Coefficient" (1), "Size" (2), "Focus" (3). The factor values within the threshold values reflect whether the studied cluster has achieved a sufficient "critical mass" to generate the positive external effects and relations. These indicators are calculated according to the employment statistics and are specified in the following formula:

$$
L Q=\frac{E_{m p_{i g}}}{E_{m p g}} / \frac{E_{m p_{i}}}{E_{m p}}
$$

where LQ is the "localization coefficient"; $\mathrm{Emp}_{\mathrm{ig}}$ is a number of employees in the cluster group $\mathrm{i}$ in region $\mathrm{g}$; Emp $\mathrm{g}$ is the total number of employees in the region $\mathrm{g}$; $\mathrm{Emp}_{\mathrm{i}}$ is a number of employees in the cluster group i; Emp is the total number of employees. 


$$
\text { Size }=\frac{E_{m p_{i g}}}{E_{m p_{i}}}
$$

where Size is the "Cluster group size"; Emp ig is a number of employees in the cluster group $\mathrm{i}$ in region $\mathrm{g}$; Emp $\mathrm{i}$ is a number of employees in the cluster group $\mathrm{i}$.

$$
\text { Focus }=\frac{E_{m p_{i g}}}{E_{m p_{g}}}
$$

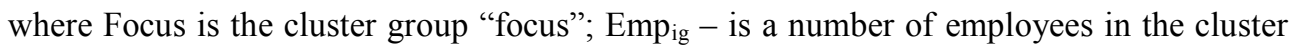
group $\mathrm{i}$ in region $\mathrm{g}$; Emp $\mathrm{g}$ is a number of employees in the region $\mathrm{g}$.

G. Lindqvist, a Swedish economist from the European Cluster Observatory [20] sets the following criteria as the threshold values that feature the meaningful cluster groups in the region:

1) "Localization coefficient" (3.1) $\geq 2$;

2) the region shall be among the $10 \%$ of the regions leading by "Size" (3.2);

3 ) the region shall be among the $10 \%$ of the regions leading by "Focus" (3.2);

Fulfillment of the constraint conditions for each indicator means assignment of a "star" to the cluster group 1. Thus, as much as possible, one or another cluster group can receive 3 "stars". A number of "stars" determines cluster group strength.

In addition, none of the "stars" can be assigned if the total number of workers in the cluster core does not exceed 1000 persons.

As a result, the implementation of the described methodology makes it possible to obtain data on a number and strength of the studied cluster groups in all regions of the studied country (group of countries).

It should be noted that the restriction by the "Localization coefficient" is a variable value. Thus, M. Porter, when studying the "core" of clusters (i.e., the clusters in the strict sense), determined the threshold value of the localization coefficient at 1.0 [17], and the US Department of Commerce uses the threshold value 1.3 [18]. In our study, when selecting the strong clusters, it is proposed to use a threshold value of 1.3.

Thus, in the course of the cluster analysis, adaptation of the results of the synthetic approach to the Russian economy makes it possible to identify the cluster "standards" typical for the studied area, and the use of the European Cluster Observatory criteria makes it possible, firstly, according to employment statistics, to check the hypothesis of a specific cluster groups strength in one region or another by a number of assigned "stars", and secondly, to identify the regions where the studied clusters are significant. The identification of such regions allows speaking both of the existence of interterritorial clusters, which accounting allows for a more effective regional policy, and the existence of competing "centers" of concentration of relevant industries capable of "draining" the employment of other cluster groups through the action of more significant positive agglomeration externalities within their territory.

The application of criteria for the level of cluster groups' development makes it possible to identify strong clusters within the country and its regions, but does not provide sufficient information about the factors of the cluster geographical concentration - agglomeration external effects which determine a level and potential of cluster group development within the studied territory. 


\section{The results of assessment of the "Information Technologies" cluster development in the regions of the Russian Federation in the period from 2008 to 2016}

To assess the development of the "Information Technologies" cluster in the regions of the Russian Federation, the authors compared the activities according to the NACE classifier, which M. Porter assigns to the "Information Technologies" cluster with the corresponding activities according to the OKVED-2001 classifier (see Table 1).

Table 1. Correlation of activity types included in the "Information Technology" cluster according to the NACE and OKVED-2001 classifiers.

\begin{tabular}{|c|c|c|c|c|}
\hline Cluster & \multicolumn{2}{|c|}{$\begin{array}{l}\text { Activities according to NACE } \\
\text { (Europe) }\end{array}$} & \multicolumn{2}{|c|}{ Activities according to OKVED (Russia) } \\
\hline \multirow[t]{2}{*}{$\begin{array}{l}\text { Information } \\
\text { Technology }\end{array}$} & 26.20 & $\begin{array}{l}\text { Manufacture of } \\
\text { computers and } \\
\text { peripheral equipment }\end{array}$ & 30.0 & $\begin{array}{l}\text { Production of office equipment and } \\
\text { computer technologies }\end{array}$ \\
\hline & $\begin{array}{l}58.21 \\
58.29 \\
62.01\end{array}$ & $\begin{array}{l}\text { Publishing of } \\
\text { computer games; } \\
\text { Other software } \\
\text { publishing; Computer } \\
\text { programming } \\
\text { activities }\end{array}$ & 72.20 & $\begin{array}{l}\text { Software development and } \\
\text { consulting in this field }\end{array}$ \\
\hline
\end{tabular}

Further, the authors calculated a level of localization, size and focus of this cluster for 80 regions of the Russian Federation for the period from 2008 to 2016 and identified 13 regions, where at least once per this period a cluster was identified in accordance with the criteria presented above. The calculation results for Moscow and St. Petersburg are presented in Fig. 1.

As of 2016, the "Information Technologies" cluster is represented in the following regions (see Table 2): St. Petersburg, Moscow, Yaroslavl Region, Novosibirsk Region, Tatarstan and Penza Region. The cluster is the largest in Moscow and St. Petersburg $-30.52 \%$ and $16.14 \%$ of all persons employed in the cluster in the Russian Federation, in this case, the cluster focus - a share of persons employed in the cluster in relation to all ones in the region - in Moscow it is increased from $0.96 \%$ to $1.2 \%$, and in St. Petersburg - from $0.58 \%$ to $1.47 \%$. High cluster localization in these cities with relatively small values of focus and size is explained by the higher population in them and by the fact that they are the main administrative, managerial and economic centers of the country. 


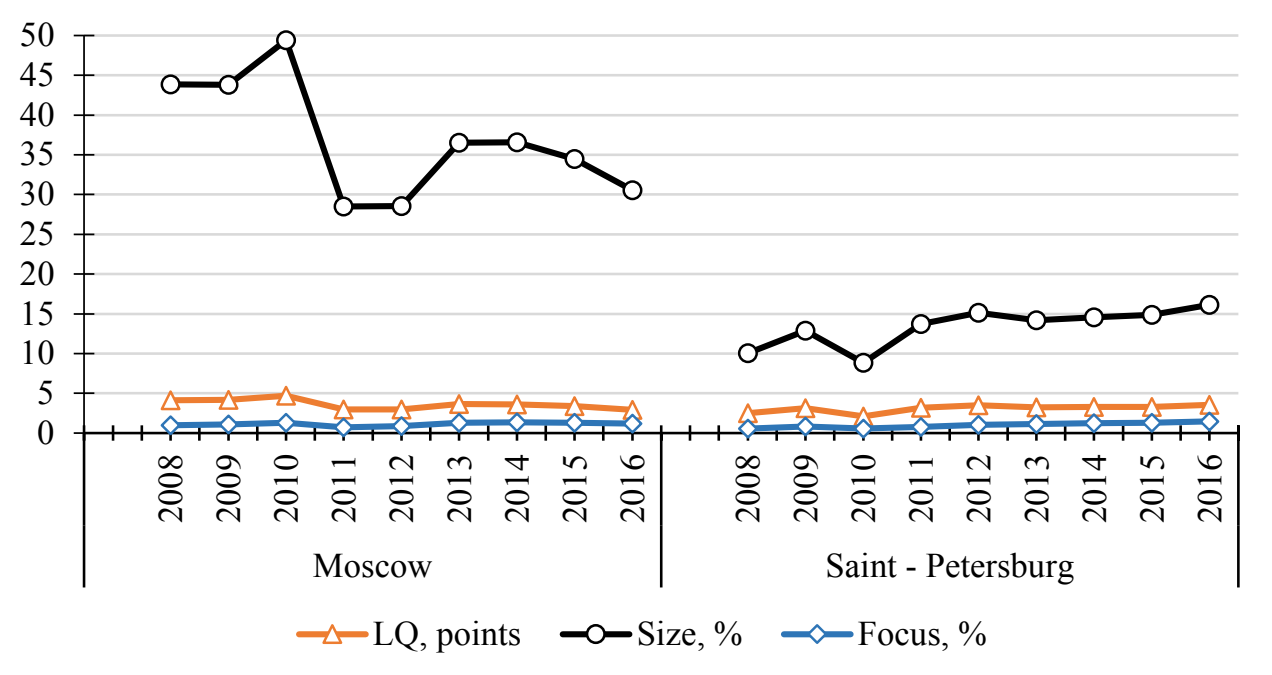

Fig. 1. Dynamics of changes in the level of localization, size and focus of the"Information Technologies" cluster in Moscow and St. Petersburg.

Table 2. A number of stars assigned to the "Information Technology" cluster in some regions of Russian Federation.

\begin{tabular}{|l|c|c|c|c|c|c|c|c|c|}
\hline & 2008 & 2009 & 2010 & 2011 & 2012 & 2013 & 2014 & 2015 & 2016 \\
\hline Republic of Bashkortostan & 2 & 1 & 2 & 3 & 1 & 1 & 1 & 0 & 0 \\
\hline Republic of Tatarstan & 1 & 1 & 1 & 1 & 1 & 1 & 2 & 2 & 3 \\
\hline Khabarovsk Territory & 0 & 0 & 0 & 2 & 2 & 1 & 0 & 0 & 0 \\
\hline Vladimir Region & 0 & 0 & 3 & 0 & 0 & 0 & 0 & 0 & 0 \\
\hline Kaluga Region & 2 & 1 & 0 & 0 & 0 & 0 & 0 & 0 & 0 \\
\hline Novosibirsk Region & 3 & 1 & 0 & 3 & 3 & 3 & 3 & 3 & 3 \\
\hline Penza Region & 2 & 2 & 2 & 2 & 2 & 2 & 2 & 2 & 2 \\
\hline Perm Territory & 0 & 0 & 0 & 0 & 1 & 0 & 1 & 2 & 0 \\
\hline Yaroslavl Region & 0 & 1 & 1 & 2 & 2 & 2 & 2 & 2 & 2 \\
\hline Kursk Region & 3 & 2 & 0 & 0 & 0 & 0 & 0 & 0 & 0 \\
\hline Nizhny Novgorod Region & 2 & 2 & 2 & 3 & 3 & 2 & 2 & 1 & 1 \\
\hline Moscow & 3 & 3 & 3 & 3 & 3 & 3 & 3 & 3 & 3 \\
\hline Saint Petersburg & 3 & 3 & 3 & 3 & 3 & 3 & 3 & 3 & 3 \\
\hline
\end{tabular}

In the period from 2008 to 2016, a stable growth of indicators characterizing the cluster development occurred only in two regions: St. Petersburg and the Republic of Tatarstan. So, in St. Petersburg, the growth of the level of the localization (ELQ) for nine years was 1.05 units, the size (ESize) by 6.09 percentage points and the focus (EFocus) by 0.89 percentage points. In Tatarstan, the level of localization increased by 0.71 units, the focus - by 0.43 percentage points, and the size by 2.24 percentage points. The simultaneous increase in all three indicators reflects the increase in specialization of these regions on the "Information Technologies".

As well as the stable presence of the "Information Technologies" cluster is observed in the Penza and Novosibirsk regions although the dynamics of its development in these regions is not unambiguous. Thus, in the Penza region there is cluster weakening over the past nine years for all three indicators. While in Novosibirsk region, despite the general trend to its 
increasing, the cluster development dynamics is characterized by constant downturns and upturns.

\section{The relationship between the regional economic growth and the development of the "Information Technologies" cluster in the Russian Federation.}

\subsection{Model, hypothesis and study method}

The relationship between the regional economic growth and the development of the "Information Technology" cluster in the Russian Federation was measured using the regression analysis tools available in the STATA MP14 program. The basic study tool was the Linear regression with panel-corrected standard errors proposed by Beck and Katz as an alternative to the feasible generalized least squares (FGLS) based algorithm proposed by Parks and Kmenta in 1986 [21, 22].

In the framework of this study, 12 models were built and tested, in the framework of which the presence or absence of relationship between the characteristics of the "Information Technologies" cluster and the GRP size was assessed. These models are divided into 4 groups depending on the hypotheses to be tested.

The first group of models can be represented as an equation as follows:

$$
\operatorname{lnGRP}_{i t}=\beta_{0}+\beta_{1} \operatorname{lnRIiFA}_{i t}+\beta_{2} \operatorname{lnTRE}_{\mathrm{it}}+\Upsilon_{\mathrm{i}} \text { ClusterIT }_{\mathrm{it}}+\phi_{\mathrm{t}} \text { Year }_{\mathrm{t}}+\varepsilon_{\mathrm{it}}+\mathrm{U}_{\mathrm{t}}
$$

where:

$\operatorname{lnGRP}_{\text {it }}$ - base logarithm of GRP (rub., in constant prices of 2008) generated in region i at time t;

$\operatorname{lnRIiFA}_{\text {it }}$-base logarithm of investments (rub., in constant prices of 2000) in the fixed capital carried out in region $i$ at time $t$;

$\operatorname{lnTRE}_{\mathrm{it}}-$ base logarithm of a number of workers employed in the region (million persons) in region $\mathrm{i}$ at time $\mathrm{t}$;

ClusterIT ${ }_{\text {it }}$ a binary variable that takes the value 1 if there is an "Information technology" cluster in the region, and otherwise, it is 0 .

Year $_{t}$ - binary variables that take the value 1 if the observation refers to a certain year $\mathrm{t}$, and otherwise, it is 0 .

For dependent and independent control variables to graduate heteroscedasticity resulting from the uneven social and economic position of the regions, the functional form of the basic logarithm was taken. In addition, the logarithmic specification of the regression equation made it possible to linearize the presented function by analogy with the Cobb-Douglas production function, which allows interpreting their coefficients as elasticity.

The H1 hypothesis is tested in the framework of the first group of models, according to which there is a statistically significant relationship between the GRP volume and the presence of the "Information Technologies" cluster in the region.

The second, third and fourth groups of models were constructed by analogy with the first one:

$$
\begin{aligned}
\operatorname{lnGRP}_{\text {it }} & =\beta_{0}+\beta_{1} \operatorname{lnRIiFA}_{\text {it }}+\beta_{2} \operatorname{lnTRE}_{\text {it }}+\Upsilon_{\mathrm{i}} \mathrm{LQ}_{\mathrm{it}}+\phi_{\mathrm{t}} \text { Year }_{\mathrm{t}}+\varepsilon_{\mathrm{it}}+\mathrm{U}_{\mathrm{t}} \\
\operatorname{lnGRP}_{\mathrm{it}} & =\beta_{0}+\beta_{1} \operatorname{lnRIiFA}_{\text {it }}+\beta_{2} \operatorname{lnTRE}_{\mathrm{it}}+\Upsilon_{\mathrm{i}} \operatorname{Size}_{\mathrm{it}}+\phi_{\mathrm{t}} \text { Year }_{\mathrm{t}}+\varepsilon_{\mathrm{it}}+\mathrm{U}_{\mathrm{t}} \\
\operatorname{lnGRP}_{\mathrm{it}} & =\beta_{0}+\beta_{1} \operatorname{lnRIiFA}_{\mathrm{it}}+\beta_{2} \operatorname{lnTRE}_{\mathrm{it}}+\Upsilon_{\mathrm{i}} \text { Focus }_{\mathrm{it}}+\phi_{\mathrm{t}} \text { Year }_{\mathrm{t}}+\varepsilon_{\mathrm{it}}+\mathrm{U}_{\mathrm{t}}
\end{aligned}
$$

where: 
$\mathrm{LQ}_{\mathrm{it}}$ - the value of the localization coefficient of the "Information technology" cluster in region $i$ at time $t$;

Size $_{i t}$ - the size of the cluster group $i$ at time $t, \%$;

Focus $_{i t}-$ the focus of the cluster group i at time $t, \%$.

In the second model the $\mathrm{H} 2$ hypothesis of statistically significant relationship between the localization level of the "Information Technology" cluster in the region and with the GRP volume, the third - the $\mathrm{H} 3$ hypothesis of the presence of positive relationship between the size of the"Information Technology" cluster in the region and with the GRP volume, the fourth - the H4 hypothesis on the presence of positive relationship between the focus of the"Information Technology" cluster in the region and with the GRP volume.

In groups of models 2, 3 and 4, the indexes: 1 corresponds to the models built based on 80 regions of the Russian Federation, 2 - based on 13 regions, where the minimum required value for two parameters of three was achieved at least once per $2008-2016$ according to the "Information Technology" cluster, 3 - based on 13 regions with an adjustment for annual fixed effects.

\subsection{Empirical results of the study}

The main empirical results of the study are presented in the Appendix. Based on these calculations, we can conclude that there is an interaction between GRP volumes and the main characteristics of the "Information Technology" cluster (see Tables 3 and 4).

So, according to the results of models $1.1-1.3$, there is a statistically significant interaction between the GRP volume and the cluster presence in the region. That is, in regions, where the presence of this cluster is recorded, the GRP level is higher on average (hypothesis H1 is confirmed).

Models $2.1-2.3$ show the presence of positive interaction between the level of local content of the "Information Technologies" cluster in the region and the GRP volume. That is, in regions, where the employment level in the "Information Technologies" cluster is higher, the GRP level is higher on average (hypothesis H2 is confirmed).

Models $3.1-3.3$ show the presence of positive interaction between the size of the "Information Technology" cluster in the region and the GRP volume. That is, in regions, where the employment share in the "Information Technologies" cluster is more relative to everybody employed in the region, the GRP level is higher on average (hypothesis H3 is confirmed).

Models $4.1-4.3$ show the presence of positive interaction between the focus of the "Information Technology" cluster in the region and the GRP volume. That is, in regions, where the employment share in the "Information Technologies"cluster is more relative to everybody employed in the region, the GRP level is higher on average (hypothesis H4 is confirmed).

In this case, these interactions are maintained even when we control in the models the volumes of investment in fixed assets by organizations, manpower in the region and annual fixed effects. 
Table 3. Empirical results of the estimation relationship between "Information technology" cluster characteristics and Gross regional product (models 1 and 2).

\begin{tabular}{|c|c|c|c|c|c|c|}
\hline MODELS & \multicolumn{3}{|c|}{ Model 1} & \multicolumn{3}{|c|}{ Model 2} \\
\hline VARIABLES & 1.1 & 1.2 & 1.3 & 2.1 & 2.2 & 2.3 \\
\hline $\begin{array}{l}\text { Whether cluster } \\
\text { "Information } \\
\text { technologies" presented } \\
\text { in the region or not }\end{array}$ & $\begin{array}{c}1.290 * * * \\
(0.144)\end{array}$ & $\begin{array}{c}\mathbf{0 . 1 5 3 * * *} \\
(0.0265)\end{array}$ & $\begin{array}{c}\mathbf{0 . 1 5 2} * * * \\
(0.0265)\end{array}$ & & & \\
\hline LQ & & & & $\begin{array}{c}\mathbf{0 . 9 3 0} * * * \\
(0.0417)\end{array}$ & $\begin{array}{c}\mathbf{0 . 0 9 9 9} * * * \\
(0.0207)\end{array}$ & $\begin{array}{c}\mathbf{0 . 1 0 4} * * * \\
(0.0189)\end{array}$ \\
\hline $\begin{array}{l}\text { Natural logarithm of real } \\
\text { investments in fixed } \\
\text { assets }\end{array}$ & & $\begin{array}{c}0.720 * * * \\
(0.0293)\end{array}$ & $\begin{array}{c}0.725 * * * \\
(0.0284)\end{array}$ & & $\begin{array}{c}0.476 * * * \\
(0.0536)\end{array}$ & $\begin{array}{c}0.474 * * * \\
(0.0489)\end{array}$ \\
\hline $\begin{array}{l}\text { Natural logarithm of } \\
\text { total regional } \\
\text { employment }\end{array}$ & & $\begin{array}{c}0.345 * * * \\
(0.0343)\end{array}$ & $\begin{array}{c}0.340 * * * \\
(0.0337)\end{array}$ & & $\begin{array}{c}0.821 * * * \\
(0.0784)\end{array}$ & $\begin{array}{c}0.820 * * * \\
(0.0724)\end{array}$ \\
\hline Constant & $\begin{array}{l}12.13 * * * \\
(0.0297)\end{array}$ & $\begin{array}{c}4.500 * * * \\
(0.332)\end{array}$ & $\begin{array}{c}4.356 * * * \\
(0.328)\end{array}$ & $\begin{array}{l}11.73 * * * \\
(0.0277)\end{array}$ & $\begin{array}{c}7.179 * * * \\
(0.624)\end{array}$ & $\begin{array}{c}7.104 * * * \\
(0.571)\end{array}$ \\
\hline Observations & 640 & 640 & 640 & 640 & 104 & 104 \\
\hline R-squared & 0.104 & 0.944 & 0.948 & 0.266 & 0.971 & 0.976 \\
\hline NumberofRegionID & 80 & 80 & 80 & 80 & 13 & 13 \\
\hline Year FE & No & No & Yes & No & No & Yes \\
\hline $\operatorname{chi} 2$ & 79.94 & 34153 & 35068 & 496.1 & 3765 & 3791 \\
\hline rmse & 1.052 & 0.262 & 0.256 & 0.952 & 0.184 & 0.174 \\
\hline
\end{tabular}

Standard errors in parentheses $* * * \mathrm{p}<0.01, * * \mathrm{p}<0.05, * \mathrm{p}<0.1$ 
Table 4. Empirical results of the estimation relationship between «Information technology» cluster characteristics and Gross regional product (models 3 and 4).

\begin{tabular}{|c|c|c|c|c|c|c|}
\hline MODELS & & Model 3 & & & Model 4 & \\
\hline VARIABLES & 3.1 & 3.2 & 3.3 & 4.1 & 4.2 & 4.3 \\
\hline Size & $\begin{array}{l}\mathbf{0 . 0 2 7 1} * * * \\
(0.00176)\end{array}$ & $\begin{array}{c}\mathbf{0 . 0 2 1 7} * * * \\
(0.00141)\end{array}$ & $\begin{array}{l}\mathbf{0 . 0 2 2 2} * * * \\
(0.00137)\end{array}$ & & & \\
\hline Focus & & & & $\begin{array}{c}\mathbf{0 . 5 8 4} * * * \\
(0.0504)\end{array}$ & $\begin{array}{c}\mathbf{0 . 3 5 1} * * * \\
(0.0556)\end{array}$ & $\begin{array}{c}\mathbf{0 . 3 0 3} * * * \\
(0.0668)\end{array}$ \\
\hline $\begin{array}{l}\text { Natural logarithm of real } \\
\text { investments in fixed } \\
\text { assets }\end{array}$ & & $\begin{array}{c}0.449 * * * \\
(0.0484)\end{array}$ & $\begin{array}{c}0.435 * * * \\
(0.0411)\end{array}$ & & $\begin{array}{c}0.483 * * * \\
(0.0489)\end{array}$ & $\begin{array}{c}0.469 * * * \\
(0.0492)\end{array}$ \\
\hline $\begin{array}{l}\text { Natural logarithm of } \\
\text { total regional } \\
\text { employment }\end{array}$ & & $\begin{array}{c}0.699 * * * \\
(0.0647)\end{array}$ & $\begin{array}{c}0.710 * * * \\
(0.0576)\end{array}$ & & $\begin{array}{c}0.804 * * * \\
(0.0734)\end{array}$ & $\begin{array}{c}0.834 * * * \\
(0.0762)\end{array}$ \\
\hline Constant & $\begin{array}{c}4.592 * * * \\
(0.321)\end{array}$ & $\begin{array}{c}7.564 * * * \\
(0.550)\end{array}$ & $\begin{array}{c}7.630 * * * \\
(0.471)\end{array}$ & $\begin{array}{c}4.334 * * * \\
(0.339)\end{array}$ & $\begin{array}{c}7.094 * * * \\
(0.567)\end{array}$ & $\begin{array}{c}7.205 * * * \\
(0.574)\end{array}$ \\
\hline Observations & 640 & 104 & 104 & 640 & 104 & 104 \\
\hline R-squared & 0.953 & 0.983 & 0.988 & 0.951 & 0.972 & 0.975 \\
\hline Number of Region ID & 80 & 13 & 13 & 80 & 13 & 13 \\
\hline Year FE & No & No & Yes & No & No & Yes \\
\hline chi2 & 47263 & 6055 & 6511 & 43222 & 2778 & 3128 \\
\hline rmse & 0.242 & 0.142 & 0.123 & 0.247 & 0.180 & 0.178 \\
\hline
\end{tabular}

Standard errors in parentheses $* * * \mathrm{p}<0.01, * * \mathrm{p}<0.05, * \mathrm{p}<0.1$

\section{Conclusion}

The relevance of measuring the impact of the information technology development on the GRP level is difficult to overestimate in the modern world. This work shows that the assessment of this contribution can be made from different sides including using macroeconomic data based on the cluster structure of the regions. Based on the theoretical and methodological developments of M. Porter and G. Lindqvist, the authors analyzed the main characteristics of the "Information Technology" cluster identified on the basis of employment data in the regions of the Russian Federation. Using the methods of econometric analysis, the authors have revealed the existence of positive interaction between the GRP volumes and the characteristics of the "Information Technologies" cluster based on the example of the regions in the Russian Federation. In this case, the positive significant interaction remained both in models built across all the regions and in models built around the regions where at least once in 2008 - 2016 the cluster existence was recorded.

It should be noted that the conclusions drawn under this study reflect the situation in the Russian Federation and the authors of future studies shall interpret these results with care when their extrapolation to other regions.

As guidelines for future studies, the authors consider it important to perform a more detailed examination of the «Information Technologies" cluster and its impact on GRP of the regions. In particular, in addition to the characteristics of the cluster based on the employment 
level, the assessment aspects Jacobian proximity effects and "Marshallian" proximity effects and their interaction to GRP volumes in the regions are relevant.

Acknowledgment: The study was performed under support of the Russian Federation President Council on Grants (project HШ - 3792.2018.6).

\section{References}

1. N. Rogge, Empirical Economics, 1-22 (2018)

2. D. G. Rodionov, I. A. Rudskaya, International Journal of Ecology \& Development, 32 (4) (2017)

3. D. G. Rodionov, I. A. Rudskaia, V. A. Degtereva Proceedings of the 29th International Business Information Management Association Conference - Education Excellence and Innovation Management through Vision 2020: From Regional Development Sustainability to Global Economic Growth (2017)

4. K. M. Vu, Information Economics and policy, 25 (4) (2013)

5. T. Niebel, World Development, 104 (2018)

6. J. Kowal, and G. Paliwoda-Pękosz, Information Systems Management, 34 (4) (2017)

7. D. Tapscott, The digital economy: Promise and peril in the age of networked intelligence, (McGraw-Hill, New York 1996)

8. M. Peitz, and J. Waldfogel, (Eds.). The Oxford handbook of the digital economy (Oxford University Press, New York, 2012)

9. J. A. Mathews, The sixth technoeconomic paradigm. In 35th DRUID Celebration Conference 2013, Barcelona, Spain, June 17, 19 (2013)

10. K. M. Vu, Telecommunications Policy, 35 (4) (2011)

11. M. Timmer, G. Ypma, and B. Van Ark, Groningen Growth and Development Centre. [online] Available at: http://www.ggdc.net/publications/memorandum/gd67.pdf. (2003)

12. D. Jorgenson, and K. Vu, German Economic Review, 8 (2) (2007)

13. Z. Latif, S. Latif, L. Ximei, Z. H. Pathan, S. Salam, and Z. Jianqiu, Telematics and Informatics (2017)

14. T. Niebel, World Development, 104 (2018)

15. L. S. Markov, V. M. Markova "Identification of reference clusters: methodological issues and practical application to the domestic industry". Vestnik NGU. Series: social and economic sciences, 12 (1) (2012)

16. E. J. Feser, S. H. Sweeney, Journal of Geographical Systems. 2, 349-373 (2000)

17. M. E. Porter, Carfax Publishing, 37 (6/7) (2003)

18. U.S. Cluster Mapping | Mapping a nation of regional clusters. (n.d.). [online] Available at: http://www.clustermapping.us/ (2018)

19. European Cluster Observatory [online] Available at: http://www.clusterobservatory.eu (2018)

20. G. Lindqvist, (Stockholm 2009)

21. N. Beck, J. N. Katz, American political science review, 89 (3) (1995)

22. D. Hoechle, Stata Journal, 7(3) (2007) 